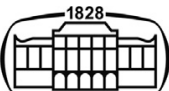

AKADÉMIAI KIADÓ

\section{Acta Veterinaria}

Hungarica

$68(2020) 3,318-322$

DOI:

$10.1556 / 004.2020 .00051$

(c) 2020 The Author(s)

\section{RESEARCH ARTICLE}

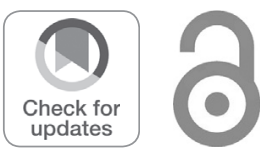

\title{
Experimental assessment of three electrosurgical tissue-sealing devices in a porcine model
}

\author{
MIKLÓS PÁL DUNAY ${ }^{1 *}$ (D, ZSUZSANNA LIPCSEY ${ }^{1}$, \\ ATTILA ARANY-TÓTH ${ }^{1}$, TIBOR NÉMETH ${ }^{1}$, \\ NORBERT SOLYMOSI ${ }^{2}$, LÁSZLÓ VENCZEL ${ }^{3}$, \\ ENIKŐ NAGY ${ }^{3}$ and JÓZSEF PAP-SZEKERES ${ }^{3}$
}

\author{
${ }^{1}$ Department and Clinic of Surgery and Ophthalmology, University of Veterinary Medicine, István u. \\ 2, H-1078, Budapest, Hungary \\ ${ }^{2}$ Centre of Bioinformatics, University of Veterinary Medicine, Budapest, Hungary \\ ${ }^{3}$ Department of General Surgery, County Teaching Hospital, Kecskemét, Hungary
}

Received: May 17, 2020 • Accepted: October 17, 2020

Published online: October 31, 2020

\begin{abstract}
Three electrosurgical tissue-sealing devices (EnSeal ETSDRC-01, LigaSure LS1500 and Thunderbeat TB-0535PC) were compared regarding sealing time (ST), maximum working temperature $\left(\mathrm{WT}_{\max }\right)$ and the total $\left(\mathrm{MTZ}_{\text {total }}\right)$ as well as the collateral microscopic thermal injury zone (MTZ $\left.\mathrm{M}_{\text {collat }}\right)$ using laparoscopic handpieces $5 \mathrm{~mm}$ in diameter on four types of tissue (liver, mesentery, cross striated muscle and spleen) in an in vivo porcine model. LigaSure had the lowest mean ST in spleen, mesentery, muscle and liver, followed by Thunderbeat and EnSeal with significant differences between all types of tissues and devices. The significantly lowest mean $\mathrm{WT}_{\max }$ was obtained for EnSeal in mesentery, muscle and liver. LigaSure and EnSeal operated at the lowest temperature in spleen without a significant difference between them. Thunderbeat produced significantly higher temperature peaks in all cases. The lowest mean $\mathrm{MTZ}_{\text {total }}$ was caused by LigaSure and EnSeal in spleen, mesentery and muscle without significant differences between them, followed by the significantly higher values of Thunderbeat. Nevertheless, Thunderbeat produced the significantly lowest mean $\mathrm{MTZ}_{\text {total }}$ in the liver. EnSeal produced the lowest mean $\mathrm{MTZ}_{\text {collat }}$ in the liver, followed by LigaSure and Thunderbeat showing significant differences. EnSeal and LigaSure produced the lowest mean $\mathrm{MTZ}_{\text {collat }}$ in the spleen, mesentery and muscle without significant differences between them, followed by the significantly higher values of Thunderbeat. Based on the results of this study, Thunderbeat seems to be more invasive to tissue integrity (even without the activation of the ultrasonic scissor function) than EnSeal or LigaSure, that operate at lower temperatures and were found to cause negligible collateral thermal damage.
\end{abstract}

\section{KEYWORDS}

Thunderbeat, LigaSure, EnSeal, tissue sealing, thermal mapping, NBTC enzyme histochemistry, microscopic thermal injury zone

\section{INTRODUCTION}

The continuously expanding toolkit of electrosurgical devices has recently become an essential accessory of everyday surgical practice in both minimally invasive and open surgical procedures (Sran et al., 2016). Thunderbeat is a relatively novel device integrating bipolar tissue-sealing function and ultrasonically generated frictional scissors. Bipolar tissue-sealing systems, such as LigaSure and EnSeal, have been widely used in the surgical practice for some time. Although a few publications have already evaluated the safety, efficacy, and versatility of electrosurgical systems (Landman et al., 2003; Lamberton et al., 2008; Person et al., 2008; Dunay et al., 2012; Milsom et al., 2012; Seehofer et al., 2012; Okhunov et al., 2018), most of the results cannot be compared objectively due to the different experimental conditions and test methods used.
${ }^{*}$ Corresponding author. Tel.: $+36(1)$ 478 4197; fax: +36 (1) 4784196 . E-mail: Dunay.Miklos.Pal@univet.hu 
Surgeons can only select the safest and most effective devices for different tissue types based on the results of standardised comparative tests. The aim of this study was to examine and compare sealing time (ST), maximum working temperature $\left(\mathrm{WT}_{\max }\right)$ and the total $\left(\mathrm{MTZ}_{\text {total }}\right)$ as well as the collateral microscopic thermal injury zone $\left(\mathrm{MTZ}_{\text {collat }}\right)$ of the three systems available at the University of Veterinary Medicine, Budapest and the County Teaching Hospital of Kecskemét, used in different tissue types under standardised conditions.

\section{MATERIALS AND METHODS}

\section{Anaesthesia}

One adult Hungarian Large White pig was anaesthetised for the procedure (by authorisation of the Veterinary and Food Inspection Station, no. XIV-I-001/1862-4/2012-2017) at the Clinic of Surgery of the University of Veterinary Medicine, Budapest. Premedication and induction were done by intramuscular administration of $0.5 \mathrm{mg} / \mathrm{kg}$ midazolam (Dormicum $5 \mathrm{mg} / 1 \mathrm{~mL}$ inj., EGIS, Hungary) and $10 \mathrm{mg} / \mathrm{kg}$ ketamine (Calypsol 500 mg/10 mL inj., Gedeon Richter, Hungary), followed by the intravenous injection of $5 \mu \mathrm{g} / \mathrm{kg}$ fentanyl (Fentanyl $0.25 \mathrm{mg} / 5 \mathrm{~mL}$ inj., Gedeon Richter, Hungary) and $5 \mathrm{mg} / \mathrm{kg}$ propofol (Propofol Fresenius 1\% inj., Fresenius Kabi, Germany). After intubation, the maintenance of anaesthesia was ensured with $2 \%(\mathrm{v} / \mathrm{v} \%)$ isoflurane (Forane $100 \mathrm{~mL}$ solution for inhalation, Abbott, UK) in oxygen gas as a carrier, and the intravenous infusion of $3.6 \mu \mathrm{g} / \mathrm{kg} / \mathrm{h}$ fentanyl and 0.36 $\mathrm{mg} / \mathrm{kg} / \mathrm{h}$ ketamine in a constant rate infusion (CRI). The pig was continuously monitored (Surgivet Advisor Vital Signs Monitor, Smiths Medical, USA) during anaesthesia, and after sample obtainment it was euthanised by the intravenous injection of $0.3 \mathrm{~mL} / \mathrm{kg}$ of euthanasia solution T61 (T61 inj. A.U.V., Intervet, The Netherlands).

\section{Surgical procedure}

Temperature measurement with a thermal camera required laparotomy. After median laparotomy EnSeal ETSDRC-01, LigaSure LS1500 and Thunderbeat TB-0535PC laparoscopic handpieces ( $5 \mathrm{~mm}$ in diameter) were used to perform tissuesealing procedures on four types of tissue (liver, mesentery, rectus abdominis muscle, and spleen). All three devices were operated at the standard setup values recommended by the manufacturer.

\section{Sealing time}

ST, the end of which is indicated by an acoustic signal, was measured with a digital stopwatch and recorded $\left(\mathrm{n}_{\text {sum }}=\right.$ 139, detailed later).

\section{Thermal mapping}

A NEC Thermo Tracer TH7700 thermal camera (NEC, Tokyo, Japan) was used to detect temperature dynamics and maximum working temperature $\left(\mathrm{WT}_{\max }\right)$ in the tissues during surgery $\left(\mathrm{n}_{\text {sum }}=115\right.$, detailed later $)$.

\section{Microscopic thermal injury zone}

Fresh samples taken from the treated tissues were quickfrozen and stored at $-20^{\circ} \mathrm{C}$ until processed and then sectioned with a Leica CM 1510-S cryostat (Leica Biosystems, Nussloch, Germany). Sections were subjected to an enzyme histochemistry test with nitroblue tetrazolium chloride (NBTC) reagent (Duchefa N1411.1000, Duchefa Biochemie, Haarlem, The Netherlands), which is capable of detecting the activity of the thermolabile lactate dehydrogenase (LDH) enzyme belonging to the group of oxidoreductases. The procedure results in a blue colour reaction outside the $64{ }^{\circ} \mathrm{C}$ isothermal line due to formazan precipitate, and no colour reaction inside the isothermal line. The $64^{\circ} \mathrm{C}$ isothermal line is considered the edge of the microscopic thermal injury zone (Dunay et al., 2012). To measure the extent of the zones in the sections, we used a SPOT Xplorer digital camera (Diagnostic Instruments, Sterling Heights, Michigan, USA) connected to an Olympus BX-60 microscope (Olympus, Tokyo, Japan) and SPOT Advanced software (Diagnostic Instruments, Sterling Heights, Michigan, USA) $\left(\mathrm{N}_{\text {sum }}=1,254\right.$, detailed later $)$.

The diameter profile of the jaws of each device was measured with digital precision slide callipers in order to calculate the individual $\mathrm{MTZ}_{\text {collat }}$ from the $\mathrm{MTZ}_{\text {total }}$.

\section{Statistical methods}

Statistical evaluation was performed with R software (Language and Environment for Statistical Computing, R Core Team, 2019) at a significance level of $P<0.05$. For the comparison of tool performance the Mann-Whitney test was performed on the recorded variables. Due to the multiple comparison issue the raw $P$ values were adjusted by the Benjamini-Hochberg approach.

\section{RESULTS}

\section{Sealing time}

EnSeal, LigaSure and Thunderbeat produced the following mean ST (seconds \pm SD) in liver: $14.45 \pm 3.75(n=11)$ vs. $4.95 \pm$ $0.47(n=10)$ vs. $8.49 \pm 3.38(n=11)$; in mesentery: $4.44 \pm 1.18$ $(n=24)$ vs. $3.65 \pm 0.34(n=21)$ vs. $8.72 \pm 4.04(n=14)$; in muscle: $9.71 \pm 2.89(n=10)$ vs. $3.72 \pm 0.51(n=10)$ vs. $7.67 \pm$ $2.96(n=10)$; and in spleen: $4.53 \pm 2.00(n=6)$ vs. $3.13 \pm 0.20$ $(n=6)$ vs. $6.12 \pm 1.51(n=6)$, respectively. Differences were significant $(P<0.05)$ between all devices and tissue types (Fig. 1).

\section{Maximum working temperature}

EnSeal, LigaSure and Thunderbeat produced the following mean $\mathrm{WT}_{\max }\left({ }^{\circ} \mathrm{C} \pm \mathrm{SD}\right)$ in liver: $63.72 \pm 6.15(n=11)$ vs. $80.37 \pm 3.06(n=10)$ vs. $90.58 \pm 4.70(n=10)$; in mesentery: $59.44 \pm 2.14(n=8)$ vs. $74.72 \pm 5.36(n=20)$ vs. $81.48 \pm 8.37(n=11)$; in muscle: $61.09 \pm 5.01(n=10)$ vs. $72.24 \pm 7.61(n=10)$ vs. $81.17 \pm 12.44(n=7)$; and in spleen: $57.33 \pm 4.49(n=6)$ vs. $54.25 \pm 9.76(n=6)$ vs. $76.83 \pm 3.02(n=6)$, respectively. Differences were 




Fig. 1. Sealing time (ST, s)

significant between all devices and tissue types except for EnSeal and LigaSure in spleen (Fig. 2).

\section{Microscopic thermal injury zone}

EnSeal, LigaSure and Thunderbeat caused the following mean $\mathrm{MTZ}_{\text {total }}(\mathrm{mm} \pm \mathrm{SD})$ in liver: $5.02 \pm 1.17(n=233)$ vs. $6.28 \pm$ $1.16(n=171)$ vs. $4.78 \pm 1.23(n=177)$; in mesentery: $4.99 \pm$ $0.63(n=139)$ vs. $4.93 \pm 0.67(n=34)$ vs. $5.61 \pm 1.05(n=75)$; in muscle: $5.30 \pm 1.08(n=89)$ vs. $5.14 \pm 1.35(n=103)$ vs. $6.58 \pm$ $1.93(n=95)$; and in spleen: $4.04 \pm 0.68(n=32)$ vs. $3.81 \pm 0.49$ $(n=32)$ vs. $4.78 \pm 0.76(n=74)$ respectively. Differences were significant between all devices and tissue types except for EnSeal and LigaSure in mesentery, muscle and spleen (Fig. 3).

EnSeal, LigaSure and Thunderbeat caused the following mean $\mathrm{MTZ}_{\text {collat }}(\mathrm{mm} \pm \mathrm{SD})$ in liver: $-0.21 \pm 0.59(n=233)$ vs. $0.58 \pm 0.58(n=171)$ vs. $0.79 \pm 0.61(n=177)$; in mesentery: $-0.22 \pm 0.32(n=139)$ vs. $-0.08 \pm 0.33(n=34)$ vs. $1.21 \pm 0.52(n=75)$; in muscle: $-0.07 \pm 0.54(n=89)$ vs.
$0.02 \pm 0.67(n=103)$ vs. $1.69 \pm 0.96(n=95)$; and in spleen: $-0.70 \pm 0.34(n=32)$ vs. $-0.64 \pm 0.24(n=32)$ vs. $0.79 \pm 0.38(n=74)$, respectively. Differences were significant between all devices and tissue types except for EnSeal and LigaSure in mesentery, muscle and spleen (Fig. 4).

\section{DISCUSSION}

In this study, the time of tissue sealing was measured in order to provide the surgeon with practical data about the speed of action of the device. LigaSure was found to be the fastest compared to Thunderbeat and EnSeal; likewise, LigaSure had the shortest sealing time compared to EnSeal in another study (Lamberton et al., 2008). According to other authors, the dissection time which includes tissue separation in addition to sealing time was shorter using Thunderbeat compared to LigaSure and EnSeal (Milsom et al., 2012). The accuracy of manual measurement with a stopwatch meets the practical

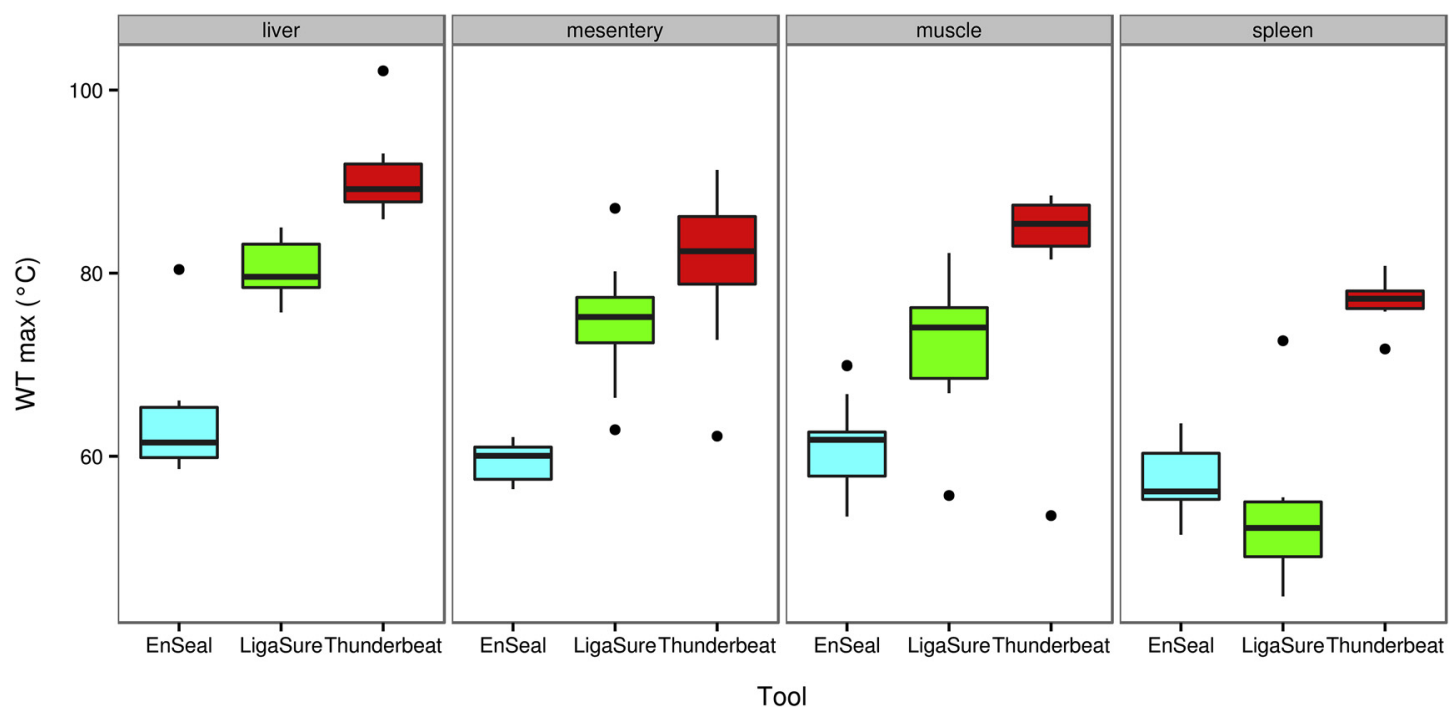

Fig. 2. Maximum working temperature $\left(\mathrm{WT}_{\max },{ }^{\circ} \mathrm{C}\right)$ 


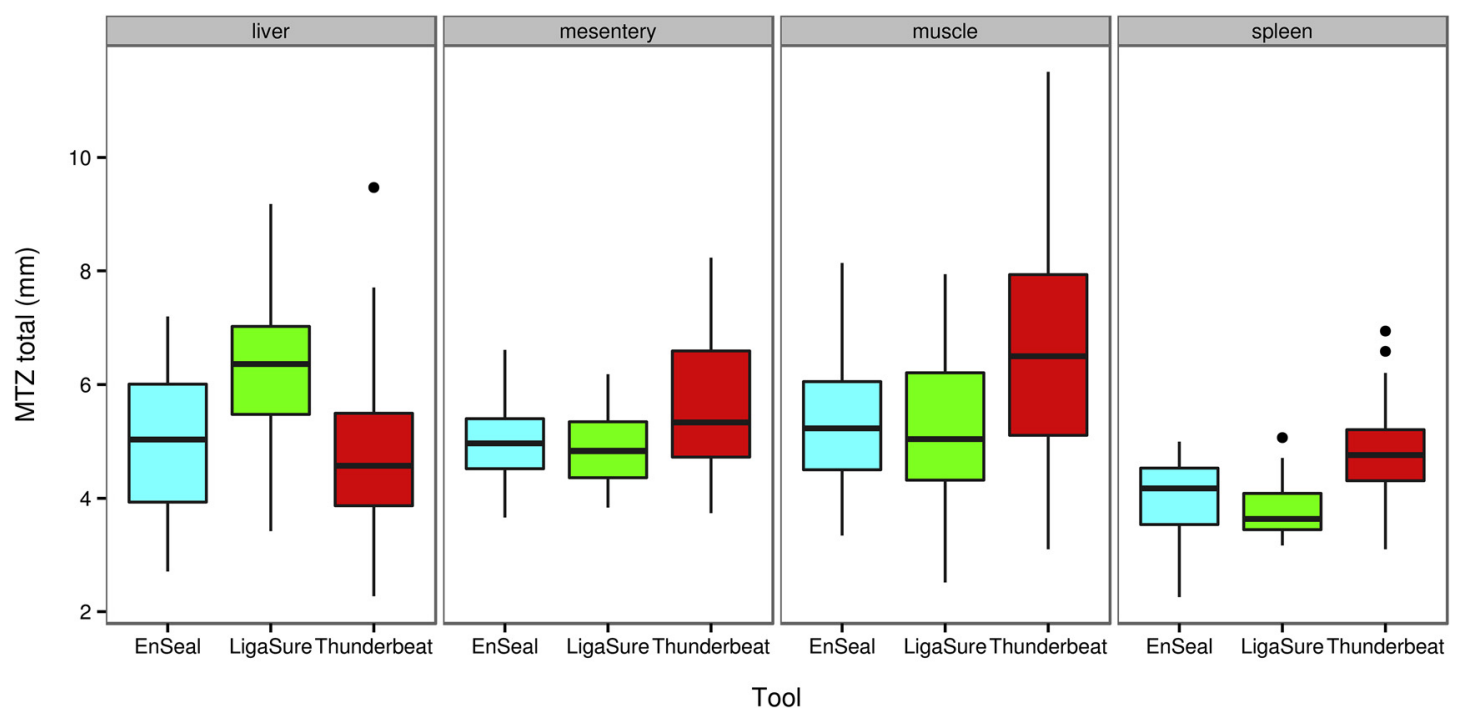

Fig. 3. Total microscopic thermal injury zone $\left(\mathrm{MTZ}_{\text {total }}, \mathrm{mm}\right)$

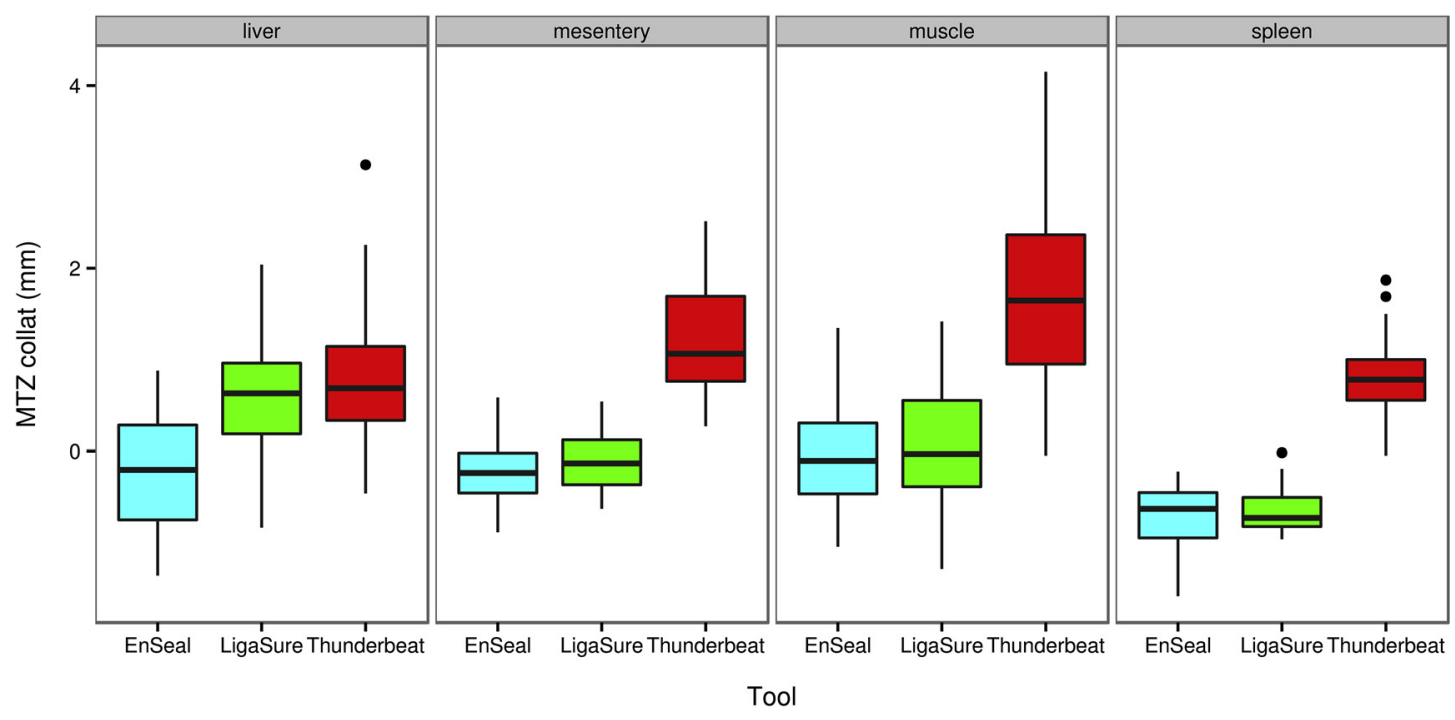

Fig. 4. Collateral microscopic thermal injury zone ( $\left.\mathrm{MTZ}_{\text {collat }}, \mathrm{mm}\right)$

criteria. Faster operation of a device, albeit to a small extent, reduces the time of surgery and anaesthesia.

EnSeal operated at the lowest mean $\mathrm{WT}_{\max }$ in all types of tissue, being not significantly different from LigaSure in splenic samples. Elsewhere, LigaSure produced the shortest time to decline to $60{ }^{\circ} \mathrm{C}$ compared to Thunderbeat (Seehofer et al., 2012). In another study thermal spread at surgery was similar between Thunderbeat and EnSeal $(P=0.6817)$, and Thunderbeat and LigaSure $(P=0.8254)$ (Milsom et al., 2012). According to our results, Thunderbeat seems to be more invasive to tissue integrity, working at significantly higher temperatures than the other devices. It should be noted that we did not use the built-in ultrasonic cutting function of Thunderbeat, which would have resulted in a temperature maximum above $200^{\circ} \mathrm{C}$ and thus a significantly larger thermal injury zone (Seehofer et al., 2012). The maximum temperature measured by the thermal camera is lower than the actual temperature peak, as it is formed in the tissues covered by the jaws. The maximum temperature is one of the most important predictors of thermal damage to the surrounding tissues, but the dynamics of temperature rise, the duration of critical temperature, and the perfusion of the tissues treated also have an impact on the effect.

NBTC enzyme histochemistry was used to measure total and collateral thermal tissue damage, since this technique is easy to apply and can precisely detect the activity zone of the thermolabile lactate dehydrogenase enzyme (Dunay et al., 2012). The sharp edge of the blue colour reaction is regarded as the expansion border of the thermal injury zone (Dunay et al., 2012). We recommend to apply this method for a standardised comparison of the thermal effects of all electromagnetic energy-based surgical devices in different tissues at different power levels and exposure times.

$\mathrm{MTZ}_{\text {collat }}$ was calculated after measuring the jaw profiles with digital precision slide callipers, which was then 
subtracted from the $\mathrm{MTZ}_{\text {total }}$ and divided by two. MTZ provides only an absolute value characterising the extension of thermal tissue damage caused by the different systems, but $\mathrm{MTZ}_{\text {collat }}$ is a minimal safety zone to be kept between the edge of the jaw and the thermosensitive tissues. The inaccuracy of the surgeon's hand movements may be greater than the $\mathrm{MTZ}_{\text {collat }}$, so it is advisable to keep a greater distance during procedures. EnSeal, either alone or together with LigaSure, caused the significantly lowest mean $\mathrm{MTZ}_{\text {collat }}$ compared to Thunderbeat depending on which tissue was examined. Interestingly, mesentery and spleen samples did not sustain thermal damage exceeding the borderline of the jaws of EnSeal and LigaSure (negative $\mathrm{MTZ}_{\text {collat }}$ values), and this was also the case for muscle and liver samples treated with EnSeal. These safety data are consistent with those found in our previous study with EnSeal (Dunay et al., 2012).

A limitation of this study is that altogether four tissue types were examined and non-standard settings of the central units were not tested.

In conclusion, based on enzyme histochemistry, Thunderbeat seems to cause more thermal damage than LigaSure and EnSeal, but all three devices minimise the potential for human error, reduce surgical blood loss, minimise the chance of metastasis, and support novel and sophisticated surgical interventions.

\section{REFERENCES}

Dunay, M. P., Jakab, Cs. and Németh, T. (2012): Evaluation of EnSeal - an adaptive bipolar electrosurgical tissue-sealing device. Acta Vet. Hung. 60, 27-40.
Lamberton, G. R., Hsi, R. S., Jin, D. H., Lindler, T. U., Jellison, F. C. and Baldwin, D. D. (2008): Prospective comparison of four laparoscopic vessel ligation devices. J. Endourol. 22, 2307-2312.

Landman, J., Kerbl, K., Rehman, J., Andreoni, C., Humphrey, P. A., Collyer, W., Olweny, E., Sundaram, C. and Clayman, R. V. (2003): Evaluation of a vessel sealing system, bipolar electrosurgery, harmonic scalpel, titanium clips, endoscopic gastrointestinal anastomosis vascular staples and sutures for arterial and venous ligation in a porcine model. J. Urol. 169, 697-700.

Milsom, J., Trencheva, K., Monette, S., Pavoor, R., Shukla, P., Ma, J. and Toyoki, S. (2012): Evaluation of the safety, efficacy, and versatility of a new surgical energy device (Thunderbeat) in comparison with Harmonic ACE, LigaSure V, and EnSeal devices in a porcine model. J. Laparoendosc. Adv. Surg. Tech. 22, 378-386.

Okhunov, Z., Yoon, R., Lusch, A., Spradling, K., Suarez, M., Kaler, K.S., Patel, R., Hwang, C., Osann, K., Huang, J., Lee, T. and Landman, J. (2018): Evaluation and comparison of contemporary energy-based surgical vessel sealing devices. J. Endourol. 32, 329-337.

Person, B., Vivas, D, A., Ruiz, D., Talcott, M., Coad, J. E. and Wexner, S. D. (2008): Comparison of four energy-based vascular sealing and cutting instruments: a porcine model. Surg. Endosc. 22, 534-538.

Seehofer, D., Mogl, M., Boas-Knopp, S., Unger, J., Schirmeier, A., Chopra, S. and Eurich, D. (2012): Safety and efficacy of new integrated bipolar and ultrasonic scissors compared to conventional laparoscopic $5 \mathrm{~mm}$ sealing and cutting instruments. Surg. Endosc. 26, 2541-2549.

Sran, H., Sebastian, J. and Hossain, M. A. (2016): Electrosurgical devices: are we closer to finding the ideal appliance? A critical review of current evidence for the use of electrosurgical devices in general surgery. Expert Rev. Med. Devices 13, 203-215. 